\title{
24. CHLOROPHYLL DERIVATIVES IN SEDIMENTS OF THE SOUTH PHILIPPINE SEA, DEEP SEA DRILLING PROJECT LEG 601
}

\author{
Earl W. Baker and J. William Louda, Organic Geochemistry Group, College of Science, \\ Florida Atlantic University, Boca Raton, Florida
}

\section{INTRODUCTION}

In order to provide a better understanding of the fate of sedimentary chlorophyll and chlorophyll degradation products in all kinds of environments, we have recently expanded our studies to include examination of sediments returned from Legs which are not rich in organic matter, nor are even primarily biogenic. Eight core samples from the Mariana Basin and Trench, obtained from DSDP Leg 60, were analyzed for products of chlorophyll diagenesis. To date, the sediment samples from the South Philippine Sea have been the most organically barren examined. Through elimination of the bias of examining only sediments rich in organic matter, we hope that the fate of chlorophyllous material on a more global scale will eventually be elucidated.

\section{METHODS}

A 200-g (wet-weight) aliquot of each core sample was exhaustively extracted with an acetone:methanol $(9: 1, v / v)$ mixture, using a ball mill. Preliminary purification of crude extracts by gel permeation chromatography (molecular sieve) on Sephadex LH-20 $0^{\mathrm{R}}$ was omitted on account of the extremely minute yields. Those samples which did yield detectable amounts of tetrapyrroles were semi-purified according to the type of pigment believed to be present. Chlorins were isolated by chromatography on microcrystalline cellulose (Merck \#2331), while isolates thought to contain metalloporphyrins were run on aluminum oxide (Grade III, Merck \#1097). Development during chromatography was with an increasing acetone gradient in petroleum ether (boiling range $30-60^{\circ} \mathrm{C}$ ).

Electronic absorption spectroscopy (i.e., UV/Vis) was utilized for determination of pigment class and yield. Tetrapyrrole pigment yield was calculated for chlorin-containing isolates, using the specific absorption coefficient for pheophytin-a $\left(\alpha=63.71 \cdot \mathrm{g} \cdot \mathrm{cm}^{-1}\right)$. This method, admittedly, biases yields to the low side, since $\alpha$-values for the more oxidized and reduced derivatives are generally less than the $\alpha$-value of pheophytin-a (see Fuhrhop and Smith, 1975). Quantitation of unidentified metalloporphyrins was not attempted because of the poor quality of spectra.

\section{RESULTS AND DISCUSSION}

Core samples from Site 452, planned as a reference for oceanic sediments (see site chapter, this volume), were all but void of chlorophyll derivatives. Absorption spectra of the total extract of Sample 452-2-5, 100-130 $\mathrm{cm}$ (16 m, sub-bottom) showed only a minor inflection in the $650-700 \mathrm{~nm}$ range (Table 1). This dearth of tetrapyrrole pigments in sediments underlying oceanic provinces has been the rule to date. The relationship between

\footnotetext{
1 Initial Reports of the Deep Sea Drilling Project, Volume 60 .
}

productivity and nutrient supplies from terrestrial influx and/or upwelling regions and the incorporation of chlorophyllous matter into oceanic sediments is well noted from our past investigations on DSDP core samples. Hole 198A (Leg 20), located at considerable distance from any significant landmass, provided core samples from the Pacific plate east of the Japan Trench. These open ocean sediments were subsequently found to be barren of detectable tetrapyrrole pigments (Baker and Smith, 1975). Recently, we examined a sedimentary sequence from the Pacific plate, cored during Leg 56. Site 436 is located just east of the Japan Trench and, as such, in a region that is probably marginal in nutrient supply and subsequent productivity. Core samples from Site 436 yielded signficantly more tetrapyrrole pigment than either Hole 198A or Hole 452 sediments. However, a rather rapid downhole demise of tetrapyrrole pigments was found for Site 436 samples (Louda et al., 1980 ) and is taken as resulting from the interplay of pre-, syn- and post-depositional oxidation in addition to the decreased productivity in the waters over Site 436. Lack of productivity in open ocean environments has been noted previously through analysis of both oceanic water columns (Yentsch, 1965) and underlying sediments (Orr et al., 1958).

For this study, Site 453 (western Mariana Trough) has provided the only potential for investigating a downhole sequence for the geochemical alteration of chlorophyllous material. This site is reported as a sediment pond east of the West Mariana Ridge containing sediments greatly diluted in organic material with volcaniclastic material (see site chapters, this volume). Tetrapyrrole yields were erratic yet could still be interpreted in terms of geologic events. Sediments analogous to Samples 453-35-3, 100-130 cm, and 453-29-2, 100-130 $\mathrm{cm}$ were deposited during a period of rapid sedimentation of primarily volcanic origin following crustal formation in the Eocene (site chapters, this volume). Burial of organic matter, even though scarce, would then have been rapid. The existence of chlorins and the indication of metalloporphyrins in the early Pliocene strata at Site 453 indicate the preservative influence of rapid burial. Shallow late Pleistocene Samples 453-2-3, 100-130 cm and $453-10-1,100-130 \mathrm{~cm}$-yielded only minor amounts of unidentifiable chlorin tetrapyrroles. Intermediate Pliocene Sample 453-18-4, 100-130 cm was void of tetrapyrrole pigments. Intense bioturbation reported for Section 453-18-4 (site chapters, this volume) attests to the prevalence of oxidative conditions during the early post- 
Table 1. Sample description and tetrapyrrole pigment yield, Leg 60.

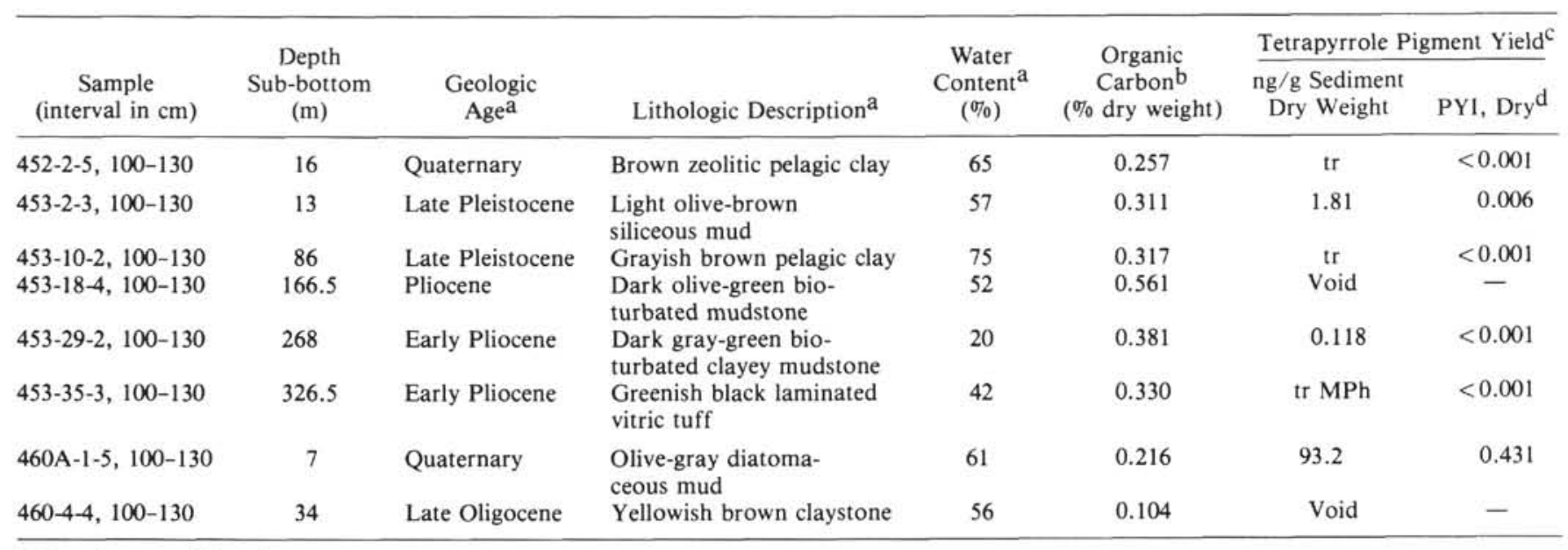

a Site chapters, this volume.

b From DSDP carbon/carbonate lab.

c Tetrapyrrole pigment yield calculated as chlorins, using the specific absorption coefficient for pheophytin-a $(\alpha=63.7)$. MPh refers to unidentified metalloporphyrin. Trace implies definite presence of pigment but in extremely low quantities and unable to be purified for valid quantitation.

d PYI, dry = Pigment yield index, dry, calculated as $\mu \mathrm{g}$ pigment $/ \mathrm{g}$ sediment, dry weight divided by percentage of organic carbon, dry weight.

depositional history of these sediments. Even though the influx of organic material, relative to overall sediment composition, was most likely higher during the deposition of Sections 453-10-1 and 453-18-4, increased exposure to oxidation has apparently effected greater removal of organic matter. This contrasts with the more organically dilute, yet more rapidly buried, deeper Site 453 sediments. Although some preservation of chlorophyll derivation occurs in the deepest strata of Site 453, it hardly could be considered petrogenic to any degree since significant organic matter is lacking (cf. Table 1).

Holes 460 and $460 \mathrm{~A}$ represent a small sediment pond deep on the inner $(\operatorname{arc})$ side of the Mariana Trench at a considerable depth of water (ca. $6450 \mathrm{~m}$, site chapters, this volume). Only the most recent sediments (Sample $460 \mathrm{~A}-1-5,100-130 \mathrm{~cm}$ ) from the inner trench wall yielded detectable tetrapyrrole pigment (Table 1). Although only $7.28 \mu \mathrm{g}$ of pigment was obtained from the initial $200-\mathrm{g}$ sediment sample, a partial purification was obtained by chromatography of the crude extract on a small $(0.5 \times$ $10.0 \mathrm{~cm}$ ) column of microcrystalline cellulose. The routine treatment of tetrapyrrole pigment isolates with diazomethane was omitted, and chlorins were then separated as either natural esters or free acids.

Isolates from Sample $460 \mathrm{~A}-1-5,100-130 \mathrm{~cm}$, fraction 1 , eluted with 1 to 3 percent acetone in petroleum ether exhibited Soret absorption at ca. $400-410 \mathrm{~nm}$ and band I absorption at $668 \mathrm{~nm}$ in ethyl ether. Fraction 1 resembled pheophytin-a and constituted less than 20 percent of the total pigment present.

Fraction 2 was isolated from extracts of Sample $460 \mathrm{~A}-1-5,100-130 \mathrm{~cm}$, eluted from cellulose with 25-30 percent acetone in petroleum ether and comprised more than 80 percent of the total pigment assemblage. Although Soret absorption is noted at $396-402 \mathrm{~nm}$, the fine structure in this region of the spectrum was obscured by the presence of blue-fluorescing, yellow-col- ored contaminants. However, Fraction 2 absorption in the red (band 1) warrants interpretation (Fig. 1). The main absorption occurs at $666 \mathrm{~nm}$, with pronounced inflections (due to overlapping absorption bands) at ca. 642 and $690 \mathrm{~nm}$, and thus indicates at least three chlorin tetrapyrroles. Considering chromatographic behavior (viz., polarity) and electronic absorption, but bearing in mind the absence of mass spectral data, we can but speculate as to pigment identity. In re-examining the electronic spectra of crude extracts and subsequent isolates, in increasing stages of purity, obtained from our studies of Japan Trench sediment samples (Baker and Louda, 1980a; Louda et al., 1980), we can offer a plausible interpretation as to the nature of underlying pigments. The inflection at $642 \mathrm{~nm}$ is characteristic of an etio-like chlorin (viz., chlorin-636) isolated from Site 438 (Baker and Louda, 1980a). This extremely defunctionalized chlorin is most likely the result of "secondary diagenesis" of free-base porphyrins (e.g., DPEP) during geologic reworking. This has been inferred from past coincidence of chlorins-636/642 with free-base porphyrins in sediments known to have input of more ancient sediments into recent strata (e.g., Site 341 Leg 38, Baker et al., 1976; Site 438 Leg 57, Baker and Louda, 1980a). The inflection of $690 \mathrm{~nm}$ seen here in the absorption spectrum of Sample 460A-1-5, 100-130 cm, fraction 2, has been shown to be due to oxidatively altered chlorins, and much evidence has been gathered to indicate these to be purpurins (viz., purpurin-18, cf., Louda et al., 1980; Baker and Louda, 1980a and b). Absorption at $690 \mathrm{~nm}$ has been ascribed to the presence of chlorophyll-d derivatives (Corcoran, 1957; Orr and Grady, 1957). While this is possible, the existence of Rhodophyceae input into these sediments is hardly likely. Furthermore, the Soret absorption of pheophytin/pheophorbide-d exhibits two almost equal maxima at 382 and $421 \mathrm{~nm}$ (cf., Smith and Benitz, 1955) and is 


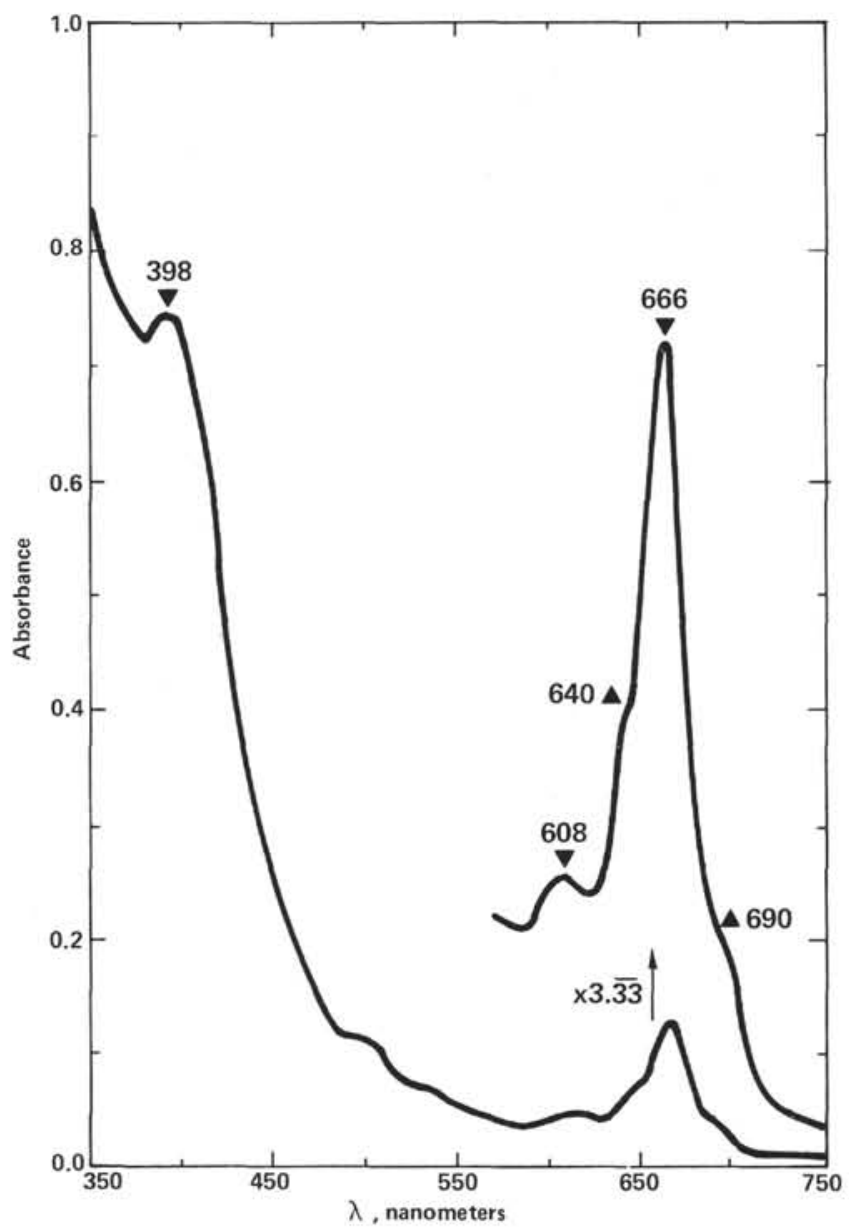

Figure 1. Electronic absorption spectrum of polar chlorins isolated from Sample 460A-1-5, 100-130 cm.

entirely unlike any geochlorin yet isolated with red absorption at $685-695 \mathrm{~nm}$ (see Baker and Louda, 1980a). "Chlorophyll-c," as an accessory pigment in Phaeophyta, Pyrrophyta, and Chrysophyta, is likely to contribute to the total tetrapyrrole assemblage in oceanic sediments. However, "chlorophyll-c" is really a porphyrin rather than a chlorin which occurs in minor quantities relative to chlorophyll-a and the demetallated product; " "pheophytin-c" lacks an isoprenoid ester moiety and has the usual property of tenaciously adhering to glass (cf., Strain, 1958). These facts would seem to rule out isolation of "chlorophyll-c" derivatives during present routine analysis, especially since absorption in the red region of the electronic spectrum is lacking for all known "chlorophyll-c"' derivatives.

The major pigment present in extracts of Sample 460A-1-5, 100-130 cm (see Fig. 1) exhibits maximum band 1 absorption at $666 \mathrm{~nm}$ and probably is one or more of the chlorin- $\mathrm{e}_{6},-\mathrm{p}_{6},-\mathrm{e}_{4}$ type pigments. This pigment is not a phorbide (e.g., pheophorbide-a and pyropheophorbide-a) as evidenced by the position of Soret absorption at $398 \mathrm{~nm}$. The phorbides with red absorption at $663-668 \mathrm{~nm}$ exhibit Soret bands at $406-411 \mathrm{~nm}$. Mixtures of chlorins and cleaved isocyclic rings and of purpurins are increasingly being identified in samples from sedimentary environments that have undergone an early history of oxidative diagenesis (cf. Baker and Louda, 1980 a and b).

\section{SUMMARY}

Oceanic sediments from Site 452, consisting of brown zeolitic pelagic clay, yielded only trace quantities of tetrapyrrole pigments. Sediments from Site 453 varied widely in volcaniclastic content, and chlorophyll derivatives could only be detected in the most recent sediments and in those which were deposited soon after crustal formation in the region of Site 453. Intermediate strata, high in volcaniclastics, were void of tetrapyrroles. Ponded sediments from the inner (arc) side of the Mariana Trench (Site 460) yielded chlorophyll derivatives only from Quaternary sediments. Recent sediments from Sites 453 and 460 yielded chlorophyll derivatives characteristic of oxidative modes of diagenesis. Extremely defunctionalized chlorins were indicated in an isolate from Sample 460A-1-5, 42-44 cm and are thought to be formed by secondary diagenetic alteration during redeposition of older sediments.

\section{ACKNOWLEDGMENTS}

This research was funded by the National Science Foundation (OCE-7913258).

The authors thank Debra Murphy and Denise Greene for assistance in initial sample preparation.

Review of the orginal manuscript by Dr. Philip A. Meyers is appreciated.

\section{REFERENCES}

Baker, E. W., and Louda, J. W., 1980a. Products of chlorophyll diagenesis in Japan Trench sediments, Site 438, 439 and 440 . In Scientific Party, Init. Repts. DSDP, 56, 57, Pt. 2: Washington (U.S. Govt. Printing Office), 1397-1408.

, 1980b. Geochemistry of tetrapyrrole pigments in sediments of the North Philippine Sea: Deep Sea Drilling Project Leg 58. In Klein, G. deV., Kobayashi, K., et al., Init. Repts. DSDP, 58: Washington (U.S. Govt. Printing Office), 737-740.

Baker, E. W., Palmer, S. E., and Parrish, K. L., 1976. Tetrapyrrole pigments in DSDP Leg 38 sediments. In Talwani, M., Udintsev, G., et al., Init. Repts. DSDP, 38: Washington (U.S. Govt. Printing Office), 785-789.

Baker, E. W., and Smith, G. D., 1975. Chlorophyll derivatives in DSDP Legs 14, 20, 26, 27 and 29 sediments. In Karig, D. E., Ingle, J. C., Jr., et al., Init. Repts. DSDP, 31: Washington (U.S. Govt. Printing Office), 905-909.

Corcoran, E. F., 1957. Quantitative studies of organic matter and associated biochromes in marine sediments. [Ph.D. dissert.]. Scripps Institution of Oceanography, University of California, San Diego.

Fuhrhop, J. H., and Smith, K. M., 1975. Laboratory methods. In Smith, K. M. (Ed)., Porphyrins and Metalloporphyrins: Amsterdam (Elsevier), pp. 757-889.

Louda, J. W., Palmer, S. E., and Baker, E. W., 1980. Early products of chlorophyll diagenesis in Japan Trench sediments of Deep Sea Drilling Project Sites 434, 435, and 436. In Scientific Party, Init. Repts. DSDP, 56, 57, Pt. 2: Washington (U.S. Govt. Printing Office), 1391-1396.

Orr, W. L., Emergy, K. O., and Grady, J. R., 1958. Preservation of chlorophyll derivatives in sediments off Southern California. Bull. Am. Assoc. Petrol. Geol., 42:925-962.

Orr, W., and Grady, R., 1957. Determination of chlorophyll derivatives in marine sediments. Deep-Sea Res., 4:263-271. 
E. W. BAKER, J. W. LOUDA

Smith, J. H. C., and Benitz, A., 1955. In Paech, K., and Tracey, M. V. (Eds.), Modern Methods of Plant Analyses (Vol. 4): Berlin (Springer), 142-196.
Strain, H. H., 1958. Chloroplast pigments and chromatographic analysis [32nd Annual Priestly Lectures, Penn. State University, University Park, Pa.].

Yentsch, C. S., 1965. Distribution of chlorophyll and pheophytin in the open ocean. Deep-Sea Res., 12:653. 